\title{
PARA FICAR EM CIMA DO SALTO: A CONSTRUÇÃO DO CORPO TRAVESTI NA PERSPECTIVA MERLEAU-PONTYANA
}

\author{
To Get on the Heels: Body Building Transvestite From the Merleau-Ponty's Perspective
}

Para Subirse a los Tacones: la Construcción del Cuerpo Travesti Desde la Perspectiva Merleau-Pontyana

EDMar Henrique Dairell Davi

Maria Alves de TOledo BRuns

\begin{abstract}
Resumo: Nosso objetivo é compreender os significados e os sentidos que travestis atribuem ao processo de transformação de seu corpo. O uso de silicone, hormônios e cirurgias para atingir a modelagem corporal se tornou algo corriqueiro entre essa população levando a um problema de saúde pública. O método fenomenológico e as reflexões do filósofo Maurice Merleau-Ponty foram eleitos por nós para analisarmos e compreendermos os discursos de três travestis pertencentes às classes sociais $\mathrm{C}$ e $\mathrm{D}$, de 25 anos de idade, em média. Os resultados apontaram três categorias: "as vivências iniciais"; "fazendo o corpo" e "o corpo desvelado na pista". Em busca do corpo perfeito, as travestis cruzam as fronteiras dos gêneros criando uma sintaxe erótica sui generis. Subvertem os sentidos do autocuidado para atender à lógica do mercado. Modelam seus corpos, equilibrando-se entre o feminino e o masculino, o desejo e o medo da violência.
\end{abstract}

Palavras-chave: Travestis; Corpo; Fenomenologia; Merleau-Ponty.

\begin{abstract}
Our objective is to understand what meanings transvestites attribute to the process of body transformation. The administration of silicone and hormones and surgeries in order to obtain the ideal body have become common place among this population and even led to public health issues. The phenomenological method and the reflections of philosopher Maurice MerleauPonty were elected for the analysis and understanding of the discourses of three transvestites of social class $\mathrm{C}$ and $\mathrm{D}$ and age 25 on average. The results generated three categories: "initial experiences"; "building the body" and "the body unveiled in the street". In their effort to shape up the perfect body transvestites cross the line between genders and create a sui generis erotic syntax. They subvert the meanings of self care in order to meet the market logic. They shape up their body balancing the feminine and masculine in them as well as their desire and fear of violence.
\end{abstract}

Key words: Transvestites; Body; Phenomenology; Merleau-Ponty.

Resumen: Nuestro objetivo es comprender los significados que las travestis atribuyen al proceso de transformación de su cuerpo. El uso de silicona y hormonas para alcanzar el modelado corporal se ha vuelto habitual entre esa población, lo que resultó en un problema de salud pública. Elegimos el método fenomenológico y las reflexiones del Merleau-Ponty para analizar los discursos de tres travestis pertenecientes a las clases sociales $\mathrm{C}$ y D, todas con un promedio de 25 años de edad. Los resultados señalaron tres categorías: "experiencias iniciales"; "hacerse el cuerpo" y "el cuerpo expuesto en la calle”. En la búsqueda por el cuerpo perfecto, las travestis cruzan las fronteras de los géneros, creando una sintaxis erótica sui generis. Subvierten los sentidos del autocuidado para atender a la lógica del mercado.

Palabras-clave: Travestis; Brasil; Cuerpo; Fenomenología; Merleau-Ponty.

\section{Introdução}

Este artigo objetiva compreender os significados e os sentidos que travestis profissionais do sexo atribuem ao seu processo de transformação corporal. No ethos contemporâneo, vivemos profundas transformações nas maneiras como lidamos com nosso corpo e nossa sexualidade - mudanças que ocorrem rapidamente, muitas vezes, sem que tenhamos a chance de pensar sobre elas e sobre suas consequências em nosso cotidiano. Para Le Breton (2011), os recentes avanços biomédicos e tecnológicos que colocaram o corpo no centro das discussões mostram o quanto este tema é enigmático.
Conhecer o corpo é uma tarefa complexa e as certezas acumuladas a seu respeito são provisórias. Cada corpo, longe de ser constituído apenas por leis biológicas e fisiológicas, supostamente imutáveis, não escapa à história e ao contexto cultural. O corpo funciona como um processador da história, por meio do qual são veiculados e modificados os legados culturais e biológicos.

Emissor ou receptor, o corpo continuamente produz sentidos - insere ativamente o homem no interior de um espaço cultural determinado. Desse modo, a construção da identidade está atrelada ao corpo, e, em alguns casos, a (re)construção do próprio corpo é uma das maneiras de o sujeito (re)significar sua identidade e estabelecer sua relação com o mundo (Le Breton, 2011). 
Assim, vemos que o corpo, lugar do contato privilegiado com o mundo, está sob os refletores e é exatamente por isso que se faz necessária uma ampla reflexão sobre a natureza dos discursos e práticas que configuram o universo da corporeidade nos dias atuais. Esta deve ser entendida como um campo de experiência e reflexão, a partir do qual se desdobram possibilidades epistemológicas, éticas, estéticas, sociais e históricas (Nóbrega, 2010).

Para Castro, García e Rodrígues (2006), grande parte dos sintomas que surgem na clínica atualmente está associada à questão da imagem corporal. Para os autores, por um lado temos os abusos na exploração das sensações corporais que determinam muitas vezes o surgimento de dependência química - de drogas lícitas e/ou ilícitas. Por outro lado, observam-se os transtornos relativos à percepção da imagem corporal e associados aos distúrbios alimentares, ao fisiculturismo compulsivo, à compulsão por correção estética cirúrgica, às ansiedades de exposição, como a síndrome do pânico e as fobias sociais etc. De certo modo, o corpo se tornou um objeto privilegiado de preocupações e sofrimentos conscientes, não se constituindo somente como pano de fundo de conflitos entre afetos, pulsões, representações e instâncias subjetivas.

Para muitas pessoas, a perfeição será atingida com o aprimoramento físico prometido pelas novas tecnologias médicas. Isso muda o perfil da idealização da imagem corporal, pois o futuro deixou de ser o tempo indeterminado de autorrealização de fantasias emocionais para ser o tempo das etapas de correção da aparência física (Castro, García \& Rodrígues, 2006).

No pensamento do filósofo francês Maurice MerleauPonty (1908-1961), o corpo é pleno de subjetividade e encontra-se recortado pela historicidade. Este filósofo não encara os seres humanos simplesmente como objetos das ciências biológicas. Além do corpo objetivo, há também o que ele denomina de "corpo fenomênico" - nosso próprio corpo tal como o experimentamos, "de dentro", um "corpo que se ergue em direção ao mundo" (MerleauPonty, 2006, p. 92).

Para este filósofo, o que movemos é nosso corpo fenomenal e não um corpo objetivo. Nosso corpo nos leva ao mundo conforme sinaliza a sua espacialidade pessoal, que é diferente da espacialidade objetiva. Este corpo fenomenal é dado na relação vivida com o sistema natural do corpo individual. É assim que um sujeito posto diante de uma tarefa familiar não precisa procurar suas mãos ou seus dedos, pois estes não são objetos a se encontrar no espaço objetivo. Músculos, ossos e nervos são potências já mobilizadas na percepção dos objetos a serem utilizados no trabalho. Vemos que os objetos dirigem certa situação, que exige certa maneira de resolução. "Ser no mundo implica em (...) manter em torno de si um sistema de significações cujas correspondências, relações e participações não precisam ser explicitadas para ser utilizadas" (Merleau-Ponty, 2006, p. 181).
Na abordagem merleau-pontyana do corpo existe uma forma de encarar os seres humanos não apenas como organismos biológicos que respondem a influências externas. Nosso corpo não é uma estrutura que existe por si mesma. Ele se estende muito além de nossas sensações do momento, pois não se encontra localizado num determinado lugar apenas fisicamente, mas expandindo-se em nosso existir no mundo. Deve ser visto como constituído não somente de sensações, mas de significações que dirigem internamente o homem no seu comportamento (Merleau-Ponty, 2004).

A subjetividade humana necessariamente se expressa por meio do corpo. E não poderia de modo algum responder subjetivamente ao mundo se não tivesse corpo. Ao mesmo tempo, meu corpo não é um mero objeto no mundo, mas algo que eu "vivo", algo que habito como veículo de minha experiência subjetiva. É tão verdadeiro dizer que meu corpo sou eu quanto que eu sou meu corpo (Merleau-Ponty, 2006).

O corpo aqui aparece não como objeto a ser possuído, "eu tenho um corpo", mas como meio de estar no mundo: "eu sou meu corpo". E ele não é uma coisa entre as coisas, é uma experiência que dialoga interiormente com o mundo, outros corpos, é com eles, no lugar de ser ao lado deles. O sujeito merleau-pontyano é um sujeito aberto ao mundo, numa relação anterior a qualquer determinação que poderíamos fazer dele: "o corpo é o veículo do ser no mundo; ter um corpo é, para um ser vivo, juntar-se a um meio definido, se confundir com certos projetos e se engajar neles continuamente" (Merleau-Ponty, 2006, p. 97).

Para Matthews (2011), a perspectiva de Merleau-Ponty sobre o corpo permite compreender o comportamento humano no nível simbólico, pois, o homem é o único animal que consegue transcender as situações e age antecipando seu futuro através de intenções e projetos. $\mathrm{O}$ ser humano não vem dotado de uma conduta preestabelecida, está aberto a respostas espontâneas e criativas, vai além do real, concebendo uma multiplicidade de possibilidades.

Ortega (2008), ao se utilizar das intuições deixadas por Merleau-Ponty, nos fala do corpo enquanto totalidade aberta, "sistema aberto para o mundo". Para aquele autor, a incorporação de próteses representa uma possibilidade de redesenhar o corpo de maneira que as extremidades se emaranhem com o mundo. As próteses se incorporam ao esquema corporal constituindo uma forma de aumentar, de expandir os limites de nosso corpo, que não acabam na pele. $\mathrm{O}$ autor cita o exemplo da bengala do cego, no qual o mundo dos objetos táteis não começa na epiderme da mão, mas na extremidade da bengala. Para Ortega (2008), as próteses ganham um estatuto de carne, permitindo ao indivíduo ampliar sua percepção desses objetos orgânicos ou inorgânicos anexados ao corpo.

Na visão merleau-pontyana, o corpo atua como ponte que nos coloca em permanente contato com o mundo revelando os sentidos de nossas ações e projetos (MerleauPonty, 2004). Norteados por esta perspectiva, nos 
perguntamos sobre os significados que as travestis atribuem ao processo de transformação corporal: o que leva uma pessoa a suportar intervenções dolorosas e arriscadas? E até mesmo a repeti-las várias vezes? O que se busca nas práticas como a aplicação de silicone e a hormonização, dentre outras?

O uso de silicone industrial, as ingestões de hormônios, as cirurgias plásticas, além de outras práticas de transformação corporal deram visibilidade à cultura travesti, que se insere no universo LGBT - lésbicas, gays, bissexuais e transgêneros. "Ser travesti" é um processo que nunca se encerra e exige constantes cuidados (Pelúcio, 2009). Construir um corpo e cuidar dele é uma das maiores preocupações das travestis, que estão sempre buscando o que chamam de "perfeição" - ou seja, "passar por mulher”. Porém, não por qualquer mulher, mas por uma mulher bonita, desejável, que atrai os olhares masculinos. Conforme Benedetti (2005), se o hormônio é a feminilidade e a beleza, que confirma os resultados da feminilização, o silicone é "a dor da beleza”. O corpo feito, todo “quebrado na plástica” é o sonho da maioria. Mas nem sempre as aplicações de silicone podem ser realizadas em clínicas de cirurgia plástica. Então, procura-se o caminho tradicional, aquele que vem sendo usado pelas travestis no Brasil há pelo menos 30 anos: o da "bombadeira". Desde então, são as "bombadeiras" que injetam silicone líquido no corpo das travestis. Elas são na sua maioria travestis também e lhes cabe "fazer o corpo" de suas clientes através da inoculação do líquido denso e viscoso - processo doloroso, demorado e arriscado (Benedetti, 2005).

O silicone comprado pelas travestis tem o aspecto oleoso, grosso, incolor e inodoro; a viscosidade dificulta as injeções no corpo humano. As "bombadeiras" costumam usar agulhas veterinárias da espessura de uma ponta de lápis e é preciso usar toda a força para injetar o silicone no corpo daquelas que pagaram pelo serviço de "bombar". São necessárias dezenas de perfurações, em dias seguidos, para se moldar o quadril, os seios ou as bochechas (Benedetti, 2005). Os orifícios deixados pela agulha são tapados com esmalte de unha ou cola. As aplicações e o mau uso dos materiais podem levar a infecções nas partes enxertadas, migração do silicone para outras áreas, dentre outras lesões.

Segundo as travestis, entrevistadas por Pelúcio (2009), a aplicação do silicone feita sem anestesia provoca uma dor quase insuportável. No entanto, para elas, essa dor se assemelha a uma ascese necessária para o renascimento à sua maneira. A questão que fica é o risco que elas correm e o preço que decidem pagar para que possam recriar a si mesmas. Será que a satisfação de ter um corpo "feminino" se sobrepõe aos riscos inerentes a esse processo? E ainda: a partir de quais critérios e influências elas resolvem fazer as intervenções? A quem recorrer quando acontecem os problemas?

Essas e outras questões perpassam o presente trabalho. Nosso objetivo é compreender os significados que as travestis atribuem ao processo de mudar seu corpo - fenômeno antigo e complexo, cujo processo ganha visibilidade nos dias de hoje. Na perspectiva de compreendê-lo em sua complexidade, buscamos a interlocução com as próprias travestis para desvelá-lo.

\section{Método}

A fim de conhecer as vivências das travestis e os significados que elas atribuem ao processo de transformação de seus corpos, recorremos à modalidade de pesquisa qualitativa fenomenológica, que nos norteará de forma criteriosa e pertinente (Bruns, 2007) na trajetória rumo à explicitação do objetivo proposto nesta pesquisa.

A opção por um método pressupõe uma questão a ser resolvida e envolve determinada concepção ou suposição de realidade, ainda que provisória. Não é possível se falar de método desvinculado do fenômeno de estudo (Furlan, 2008). Nesse sentido, nossa escolha traduz uma posição em termos epistemológicos e um método de inspiração fenomenológica parece o mais adequado quando se pretende investigar e conhecer a experiência do outro, uma vez que o ato do sujeito de contar a sua experiência não se restringe a dar a conhecer os fatos e acontecimentos da sua vida, mas significa, além de tudo, uma forma de existir com-o-outro; significa com-partilhar o seu ser-com-o-outro.

Por ser a fenomenologia um discurso esclarecedor, optamos pela técnica da história de vida focal, guiada por uma questão única, simples e direta, numa linguagem comum à compreensão do fenômeno, como estratégia de pesquisa para desvelarmos a vivência das travestis e o processo de transformação de seus corpos.

É importante ressaltar que a história de vida focal é uma modalidade da história oral em que o informante tem maior liberdade para dissertar livremente sobre suas experiências vividas, o que vai ao encontro do objetivo de nossa pesquisa. Para Moreira (2004), o método da história de vida focal investiga a visão da pessoa acerca das suas experiências subjetivas de certas situações, inseridas em algum período de tempo de interesse, ou se refere a algum evento ou série de eventos que possa ter tido algum significado para o respondente. O colaborador faz uma descrição de sua vida ou de alguma parte dela.

\section{Procedimentos}

Primeiramente, o projeto que embasa esta pesquisa foi encaminhado ao Comitê de Ética em Pesquisa - CEP da FFCLRP/USP para sua devida aprovação. Após a emissão do parecer favorável ao início da investigação, entramos em contato com as colaboradoras, para quem foi entregue uma carta apresentando o objetivo da pesquisa e solicitando o agendamento da entrevista. Esta foi precedida da 
assinatura do Termo de Consentimento Livre e Esclarecido, que autorizava sua gravação. Também foi aplicado um questionário socioeconômico para traçar o perfil das participantes. As entrevistas tiveram a duração média de 60 minutos. Para um maior aprofundamento da experiência pessoal das entrevistadas em relação ao fenômeno estudado, iniciamos com a questão orientadora: "Fale da sua vivência afetivo-sexual em relação ao processo de transformação de seu corpo durante a sua vida”. Os encontros foram realizados na sede de uma ONG de apoio à população LGBT, localizada numa cidade do interior do Estado de Minas Gerais.

\section{Participantes}

As colaboradoras desta pesquisa foram três travestis frequentadoras das reuniões da citada ONG de apoio à população LGBT. Os critérios para a inclusão das participantes na investigação foram: aceitar participar da pesquisa e ser travesti que tenha passado pelo processo de transformação corporal - seja pelo uso de hormônios e/ ou pela aplicação de silicone.

A seguir, apresentamos o perfil socioeconômico das colaboradoras. Antes, no entanto, é preciso esclarecer que optamos pelo uso de pseudônimos a fim de preservar nossas colaboradoras. Esclarecemos, ainda, que o motivo pelo qual nos dirigimos a elas no feminino se deve ao fato de se sentirem e se definirem a partir deste gênero.

A primeira colaboradora entrevistada foi Adriana, uma travesti de 24 anos, com ensino médio completo, sem religião e pertencente à classe D. Ela atua em uma ONG de apoio às travestis elaborando projetos de intervenção junto a esta população. A segunda, chamada Brenda, é uma travesti loira de 27 anos, sorridente e "toda feita", conforme seu depoimento. Estudou até o quinto ano do ensino fundamental, não possui religião, pertence à classe $\mathrm{C}$ e vive com um parceiro fixo. É uma profissional do sexo. A terceira e última travesti entrevistada foi Jéssica, de 25 anos, que veio do norte do Brasil. Tem a pele morena, não possui religião, pertence à classe $\mathrm{D}$ e cursou o ensino médio. Atua como profissional do sexo desde os doze anos de idade e já morou em várias cidades do Brasil.

\section{Momentos da análise}

Tendo nas mãos os depoimentos ou descrições das colaboradoras, passamos à análise das entrevistas. Bruns (2007) aponta quatro passos reflexivos para realização da análise fenomenológica. O primeiro passo caracteriza-se pela transcrição dos depoimentos das colaboradoras e leitura ampla de todas as entrevistas do início ao fim, com o objetivo de apreender o sentido geral do fenômeno estudado. O segundo momento é marcado pela intenção de caminhar para a elaboração da discriminação das unidades de significado, as quais são extraídas após a releitura de cada depoimento, tendo em vista que não existem por si mesmas, mas somente em relação à interrogação que o pesquisador dirige ao fenômeno. O terceiro passo diferencia-se pelo seguinte aspecto: após a obtenção das unidades de significado, o pesquisador busca agrupá-las em temas ou categorias, que expressam o insight psicológico nelas contido, ou seja, é a transformação da linguagem coloquial da entrevistada no discurso psicológico. Neste momento cabe ao pesquisador escolher a abordagem teórica que utilizará para analisar o fenômeno. O quarto e último passo baseia-se na integração dos insights contidos em todas as unidades de significado, as quais podem ser agrupadas em temas ou categorias em função das convergências e/ou divergências dos significados atribuídos pelas informantes e que constituem os aspectos essenciais da estrutura compreensiva geral do fenômeno.

\section{Resultados}

\subsection{Categorias de análise}

De posse dos depoimentos, a partir dos passos já apresentados anteriormente para o acesso ao fenômeno e da análise compreensiva que nos possibilitou o encontro das convergências e divergências presentes nos discursos, elegemos as seguintes categorias:

Categoria 1 - Vivências iniciais: nesta categoria, as colaboradoras relataram os momentos e as maneiras como iniciaram suas primeiras experiências e vivências do processo de transformação do corpo.

Categoria 2 - Fazendo o corpo: nesta categoria, deparamo-nos com as experiências vividas pelas colaboradoras durante o processo de transformação do corpo de maneira mais radical, com o uso de hormônios e silicone. Temos, aqui, 02 subcategorias: Hormonização e Plastificando o corpo.

Categoria 3 - O corpo desvelado na pista: nesta categoria, as colaboradoras revelam como o corpo também é moldado na experiência da prostituição.

\subsection{Análise compreensiva}

As entrevistas são analisadas conjuntamente, demonstrando as convergências e divergências dos depoimentos, que formam as categorias de análise. Desse modo, passamos à discussão da primeira categoria: As vivências iniciais.

Com dez anos então eu comecei a me vestir de mulher e com doze eu comecei a vida na prostituição lá em B. num posto de gasolina. Então eu tive assim uma vida de prostituição muito precoce, muito menininha. 
Na batalha [prostituição] você aprende de tudo, é uma escola. Te ensinam a aquentar [esconder o pênis], ficar montada em cima do salto [bonita], te explica as coisas dos bofes, das cafetinas, essas coisas de travesti, sabe? (Adriana)

Eu passei a virar travesti lá na minha cidade, S. L. no $M$., que eu passei a virar mesmo travesti foi a partir mesmo dos 20 anos. Eu tive muita dificuldade pra estudar porque eu já queria ir pra escola de mulherzinha, de botinha, de blusinha. Isso lá na quinta ou sexta série eu já tinha essa tendência homossexual. Não lembro direito. Aí tinha chacota de todo mundo, sabe? (Brenda)

Eu gosto de me travesti mesmo desde a adolescência quando eu estudava. Com doze anos eu já me assumi como homossexual, já com doze anos eu já usava roupa de mulher. Lógico que meu pai se revoltou com isso e se separou da minha mãe. Me prostituo desde os doze anos. Desde os doze anos quando eu comecei a me vestir de mulher, os homens começaram a me cantar. E a partir desse momento eu passei a cobrar pelo meu sexo. (Jéssica)

No depoimento das colaboradoras, podemos observar que a vivência do travestir se inicia bem jovem, no começo da adolescência ou ainda no período da pré-adolescência. O começo da experiência travesti é marcado pela identificação com o feminino e características socialmente determinadas desse fenômeno (adereços, peças de roupa, maquiagem, postura etc.). A idade do assumir-se travesti depende, em muito, de condições como a relação com a família, da cidade de residência, dos aspectos econômicos, dentre outros (Kulick, 2008).

No caso de Adriana, observa-se a presença de amigas que serviram como modelo de construção do feminino e como "tutoras" para elaboração do seu travestir-se. Pelúcio (2009) afirma que muitas travestis orgulham-se de serem "mães" ou madrinhas, o que, por vezes, tem o mesmo sentido. "Amadrinhar" geralmente se refere a proteger e ensinar a viver como travesti, cabendo à categoria de mãe a iniciação propriamente dita. A noção de "mãe" entre as travestis está ligada, portanto, ao processo de transformação. Muitas travestis saem de casa ainda "gayzinhos", denominação que indica que ela já assumiu sua orientação sexual para familiares e para a "sociedade", mas ainda não se vestem com roupas femininas ou ingerem hormônios.

O momento de se revelar homossexual e de se apresentar aos outros como travesti depende de vários fatores como o tipo de discriminação que o indivíduo irá enfrentar e o apoio com o qual poderá contar. Brenda foi humilhada na escola e, no caso de Jéssica, observamos o preconceito de seu pai ao saber de sua orientação sexual. Mas não basta assumir-se. A partir desse momento, muitas travestis, quando são expulsas de casa ou rompem com a família, passam a contar somente com suas forças para se manterem. É dessa forma que o dinheiro da prostituição aparece como uma primeira forma de sustento. Contudo, como profissional do sexo, não é somente o ganho material que elas recebem.

Para Peres (2015), as jovens travestis se envolvem em relações sexuais muitas vezes sem a perspectiva de ganhar dinheiro ou de ter prazer nestas relações. O que elas ganham, e isso é muito importante para elas, é o reconhecimento de que são mulheres ou são femininas. Peres (2015) ainda afirma que as travestis não obtêm sexo de seus parceiros, mas sim gênero. Ao ser "cantada", Jéssica recebe a confirmação de sua feminilidade, de seu corpo e do investimento neste corpo.

Para Merleau-Ponty (2006), o corpo é também uma forma de expressão e comunicação com o mundo que demarca o campo da linguagem a partir da percepção do sujeito, uma vez que atribuir sentidos ao mundo é também comunicá-los e a relação com o outro só ocorre à medida que se estabelece estratégias de compreensão. Ao se travestirem e irem para a "batalha", nossas colaboradoras comunicam aos homens sua disponibilidade para possíveis relações afetivo-sexuais e recebem deles, através dos olhares, brincadeiras e galanteios, a confirmação do seu aspecto feminino. Os elogios ou as críticas de outras travestis também representam uma forma de se observar a construção do feminino no corpo e do alcance ou não da meta de se passar por mulher. Merleau-Ponty (2006) diz que eu só consigo apreender a intencionalidade do outro - e sua atitude para comigo - porque através do meu corpo posso torná-la minha.

A partir de seus relatos, observamos que o aprendizado das colaboradoras demonstra a complexidade desse processo que vai desde a preparação do corpo travesti (se montar) até a maneira de lidar com os clientes na prostituição. Observa-se, além disso, o uso de uma linguagem específica utilizada no dia a dia das travestis. A linguagem, como a rede de amizades, serve de proteção às travestis para se comunicarem, por exemplo, diante de um freguês perigoso sem que ele perceba o que está sendo dito ou até mesmo para avisar sobre a chegada da polícia.

As travestis mais velhas são responsáveis pela iniciação das mais novas e as orientam durante o processo de "fazer o corpo". Isso pode ser observado no depoimento das colaboradoras sobre o começo da Hormonizaçãa:

Então eu comecei muito jovem mesmo já me travestindo porque eu via as minhas amigas e queria ser igual a elas.E elas mesmas me davam hormônios anticoncepcional nas cartelinhas, me mandavam bater com vitamina, a gente fazia isso e tomava todo dia. E muita injeção com aqueles hormônios femininos. Pra ralear o sangue, pro chuchu [barba] ficar sem aparecer. (Adriana) 
Pra assim, fugir dos tombos que a gente leva, eu resolvi ser cabeleireiro. No salão ser mona é tranquilo. Tomar hormônio, cabelo grande. Eu vi que era o hormônio que separa a travesti do gayzinho. Porque modifica o corpo, então eu queria ser travesti. Você conhece muita gente que te ensina a transformar. (Brenda)

\section{Eu tomei hormônios até os dezessete anos. Quando eu viajei eu conheci o silicone industrial. (Jéssica)}

Investigando o processo de construção corporal das travestis, das drag-queens e das transformistas, Jaime (2010) observou que a ingestão de hormônios é um artifício diferenciador entre as pessoas no universo trans. Para as travestis, há a necessidade de ser mulher 24 horas por dia, nisso os hormônios têm uma importância fundamental por que alteram o corpo, o humor, a voz, o desejo sexual, dentre outros aspectos. Transformistas e drag-queens geralmente vivenciam mudanças mais superficiais por tempos limitados, como nas apresentações, e em ambientes específicos.

Observa-se entre as travestis uma diversidade de denominações: os "travecões" salientam suas formas com o excesso de silicone, enquanto as "ninfetinhas" exageram menos nos trejeitos e adereços. Por fim, as chamadas tops constroem seus corpos em clínicas especializadas em estética. Nesse sentido, pesquisadores utilizam o termo travesailidades para caracterizar a diversidade deste universo (Pelúcio, 2011).

A transformação do corpo travesti é impulsionada pela ação dos hormônios. Sua eficácia simbólica de trazer os aspectos do feminino para um corpo masculino pode ser observada nos depoimentos das colaboradoras. Kulick (2008), em pesquisa acerca das travestis de Salvador, aponta que a fase dos hormônios é imprescindível porque marca o inicio do processo de transformação mais profunda do corpo. Elas começam a "se realizar" como travestis. Muitas vezes por estarem já fora de casa e por precisarem de dinheiro para se manter, as travestis investem no uso dos hormônios para se estabelecerem de vez na prostituição. A forma arredondada dos corpos atrai os olhares e o crescimento dos seios transforma a silhueta de um corpo masculino em um protótipo do feminino.

Travestis mais velhas e experientes costumam encorajar as jovens a tomar hormônios, sabendo que quanto mais cedo for iniciada a hormonização melhor será seu efeito. Os hormônios agem sobre os pelos, sobre a voz e sobre as formas da travesti, fazendo com que ela obtenha um corpo com a menor quantidade de atributos masculinos. Isso no mercado concorrido da prostituição se refletirá no número de programas, no dinheiro arrecadado e na sua imagem frente às outras travestis (Pelúcio, 2011). Mas, a medida que os hormônios vão fazendo seu efeito, é preciso dar um salto em busca de um corpo mais feminino: entra em cena o silicone. Nossas colaboradoras afirmaram o seguinte sobre o momento de plastificar o corpo:
Depois de um tempo eu bombei silicone no bumbum. E com o passar do tempo, acho que tem uns dois anos que eu pus prótese no seio, acho que foi uma conquista. Porque as travestis quando não consegue por prótese de silicone e tem que se submeter ao silicone industrial é o ó! [perigoso]. Pra nós é uma conquista. Eu me considero uma vitoriosa por isso, de ter conseguido isso. Acho que é um primeiro passo, né. (Adriana)

Parei com o hormônio fui pra SP. Foi lá que comecei a pôr silicone no meu corpo. Nas primeiras vezes eu morri de dor. Mas aí vai ficando duro e você passa a aguentar. Na verdade dói só nas primeiras agulhadas, né. Tem que tomar remédio depois. Isso a bombadeira ensina. Mas como as meninas falam é a dor da beleza, né. Eu acho isso certo porque a mulher não passa dor pra ficar bonita? Então, a gente também sofre pra ficar em cima do salto [bonita], né. Hoje eu tenho uns sete litros de silicone. Aí quando o repouso é feito certinho a tendência é só coisas boas. (Brenda)

O começo do silicone foi complicado porque eu tive problema. O meu primeiro silicone ele rejeitou. Eu tive de mandar drenar o silicone, entendeu? Foi uma fase muito difícil, mas como travesti eu me fiz de novo continuei fazendo pista, depois que sarou tudo. E depois de alguns anos eu voltei a injetar novamente. Claro que eu trago marcas do primeiro defeito que aconteceu, por pouco não teve que amputar a minha perna. (Jéssica)

Muitas travestis dizem que o silicone é algo "divino" porque transforma o corpo rapidamente. Mas o desejo de ter um corpo feminino "bombado" se sobrepõe aos riscos implicados nessa construção. Como observou Sabino (2004) em sua pesquisa entre fisiculturistas cariocas, antes de julgar esses procedimentos utilizados na busca de um corpo específico como ignorância ou irracionalidade, devemos observar o aspecto social que confere significado à tal prática. Esta, frequentemente, está imersa em sistemas simbólicos com lógica própria, onde a dor e o sacrifício aparecem como preço a ser pago e possibilitam a aceitação em grupo restrito.

Para Jéssica, que não conhecia o silicone industrial, o processo de "bombar" representou sua entrada definitiva no mundo das travestis e com ele compactuar; inobstante os riscos e danos que disso decorressem. Do depoimento de Adriana pode-se extrair que ter uma prótese no seio colocada em uma clínica é uma conquista por que realmente poucas têm essa possibilidade. As travestis conhecem vários casos infelizes de aplicação pelas "bombadeiras": peitos que praticamente se fundiram por causa do deslizamento do silicone, causando inchaço pronunciado e indistinto, denominado por elas "peito de pomba", ou casos em que o silicone formou nódulos protuberantes bem acima do estômago (Pelúcio, 2009). 
Obter recursos para colocar a prótese, como nos relata Adriana, "é uma conquista" para poucas. Isso se reflete no número de programas e no ganho diário. Podemos observar também que essa valorização da prótese, que aumenta e realça os seios deixando-os diferentes daqueles formados por hormônios, se deve a mudanças no padrão de beleza das mulheres brasileiras nos últimos anos. Don Kulick, nos anos de 1990, falava da valorização ainda presente da bunda e dos quadris pelos brasileiros (Kulick, 2008). Hoje, se observa maior influência do modelo americano que valoriza o busto (Pelúcio, 2011). Essa mudança também se reflete na estética das travesti mais jovens que fazem a linha ninfetinha, com a silueta mais clean e menos travecão, com excesso de hormônio e silicone, conforme apurou Jayme (2010).

Sobre a relação das travestis com o silicone, seja industrial ou em próteses, podemos pensar como Merleau-Ponty (2004) quando discute nossa relação com os objetos e os significados que atribuímos a eles. O filósofo afirma que os objetos e nossas preferências em relação a eles, que fazem parte do nosso mundo, são parte de nossas escolhas e provocam em nós reações boas e ruins que acabam por refletir em nós mesmos. Pois ainda que haja a tentativa de elaboração discursiva do que é o mundo, do que sou eu, concretamente o mundo só aparece na minha interação com ele, na minha vivência, me afetando e sendo afetado por mim.

A ausência de pesquisas específicas sobre essa realidade vivida pelas travestis impossibilita uma discussão mais acurada sobre os efeitos do silicone industrial aplicado em seus corpos, assim como, do uso abusivo e indevido de hormônios sem orientação, deixando-as à mercê de práticas nem sempre saudáveis e que nem sempre observam as condições de higiene necessárias a tais procedimentos (Benedetti, 2005). Algumas terapias próprias da medicina autorizada, como o uso de anestésicos, ingestão de antibióticos, são incorporadas a estes cuidados, mas, na maioria das vezes, são administrados pela "bombadeira" ou por uma travesti mais experiente.

O processo de colocar o silicone constitui um dos pontos da transformação travesti, mas é também na prostituição que esse corpo se moldará. Desse modo, em relação à categoria $\mathbf{O}$ corpo desvelado na pista, nossas colaboradoras relataram que:

E a prostituição / até hoje eu faço prostituição / ainda vou pra rua porque infelizmente eu não tenho como me sustentar. Porque com a prostituição a gente sabe que fica muito exposta às DST, a AIDS, ao álcool, às drogas. A saúde mental das travestis atualmente anda um pouco avariada porque a gente é muito grande o uso e abuso das dependências químicas devido às circunstâncias, devido ao meio que a gente vive mesmo. (Adriana)
Já trabalhei como cabeleireiro, mas eu gosto mais da prostituição. E com o silicone você tem mais programa. E também, os cliente acham que eu tenho pauzão [risos]. E aí dou sorte. Sempre me escolhem. Porque o que eles querem é pauzão. (Brenda)

Eu preciso comer, me vestir, me calçar. E é muito fácil um homem chegar pra mim e se oferecer, é muito mais fácil um homem me oferecer sexo do que me oferecer um prato de comida ou um copo de água. Sabia? É mais fácil ele querer me passar o sal do que ele querer me ajudar. Se eu for pedir dinheiro pra passagem do ônibus eles logo perguntam "o quê que você vai fazer pra mim? Não quer chupar aqui, não?” Entendeu? (Jéssica)

Ao expor seu corpo no mundo da prostituição, as colaboradoras nos revelam os riscos e perigos dessa vivência. Para Merleau-Ponty (1975), o espaço, seja da escola ou da casa onde moramos, é a delimitação concreta dos limites do corpo e se estabelece pelo contexto sociocultural no qual a pessoa está inserida. Sob este aspecto, os modos de interação do corpo com o mundo bem como o modo como este será percebido, compreendido e significado estão, também, delimitados pela lógica deste espaço, adquirindo os traços culturais, hábitos, práticas que se tornam constituintes de nossa subjetividade e dão significados e sentidos ao nosso lugar no mundo e ao existir.

O espaço é existencial; poderíamos dizer da mesma maneira que a existência é espacial, quer dizer, que por uma necessidade interior ela se abre a um 'fora', a tal ponto que se pode falar de um espaço mental e de um "mundo das significações e dos objetos de pensamento que nelas constituem. (Merleau-Ponty, 2004, p. 74)

Também é importante destacar que em momento algum se deve pensar que a prostituição e a travestilidade sejam indissociáveis. Para Pelúcio (2009), entretanto, a opção por pensar a travestilidade recortada pela vivência na prostituição é legítima, tanto mais quando se observa que o universo das ruas (a pista) é fundamental na construção da pessoa travesti; é onde ocorre, por exemplo, o processo de amadrinhamento, que, como vimos acima, potencializa as transformações realizadas no fazer-se travesti.

Ainda conforme Pelúcio (2011), a prostituição no caso das travestis pode ser entendida de diversas formas: (1) um trabalho, que gera renda e possibilita um ambiente de sociabilidade; (2) um meio de ascender socialmente com a garantia de conquistas materiais e simbólicas; (3) uma atividade "desprestigiada", em que estariam envolvidas somente por necessidade financeira e da qual sairiam assim que possível, dentre outras. É ainda importante ressaltar que tais posicionamentos não são estanques e/ou definitivos e sim percepções que se entrecruzam e dialogam.

Adriana procura outras formas de se sustentar atuando como voluntária em uma ONG de apoio às travestis. 
Brenda e Jéssica atuam como profissionais do sexo e procuram trabalhar com dignidade e longe dos riscos - que parecem ser muitos: drogas lícitas e ilícitas, violência, doenças, entre outros. O corpo travesti é um corpo que também se faz pela resistência aos perigos (Andrade, 2015).

$\mathrm{O}$ rol de dificuldades pelas quais passam as travestis que estão "na pista", é longo - repressão policial, assaltos, brigas, ofensas proferidas pelos transeuntes. Até pegar a "manha", medo e insegurança são situações de ameaça enfrentadas pelas travestis que se prostituem. O corpo precisa aprender a suportar o frio, os longos períodos em pé, o sono e muitos outros desafios. No entanto, aquilo que chama a atenção nos relatos das colaboradoras é o lugar de abjeção reservado ao seu corpo.

Para levar a cabo a construção desse corpo e desse gênero, as travestis desenvolvem todo um "rebolado" para lidar com as constantes situações de discriminação a que estão submetidos os "abjetos", "anormais" e "diferentes". Procuram manter-se "no salto" apesar dos muitos tropeços reservados para os que enfrentam as fronteiras de gênero insistentemente demarcadas. Peres (2011) acredita que esse processo de "degradação" das travestis ocorre por dois motivos. O primeiro consiste em que, estando imersas numa sociedade machista, elas fogem do papel de macho, de provedor e, ao feminilizar seu corpo, este perde seu status social, tornando-se uma"coisa abjeta", inexistente e não importante. Já no segundo desvio é que, ao adentrarem na prostituição, tornam-se uma chaga social, uma praga que precisa ser extirpada.

Nesse sentido, Merleau-Ponty (2006) afirma que o estabelecimento de julgamentos e estereótipos ao outro faz com que ele se transforme nesta realidade para o sujeito, sem necessariamente haver uma reflexão sobre ele, sem amparar-se no aspecto fenomênico, devido à recorrência das experiências. Ou seja, a frequente discriminação faz com as travestis naturalizem a violência e o preconceito, colocando-se como pessoas de segunda classe, à margem da sociedade.

É preciso lembrar que o homem é ser falante e que pela sua fala visa as coisas enquanto elas estão ausentes. Assim, uma palavra é "um de nossos possíveis de meu corpo próprio" e por ela a "existência dar-se-á como coexistência, como comunicação e diálogo" (Merleau-Ponty, 2004, p. 164). Nessa perspectiva podemos perceber relações intrínsecas entre a experiência vivida pelas travestis em suas trajetórias existenciais e os significados e valores que são atribuídos às figurações, aos discursos e aos desejos que se processam em decorrência da própria experiência de vida, demarcando preconceitos e exclusões, analisados através de estruturas binárias, consideradas inerentes aos indivíduos. Para Estrada-Mesa e Báez-Silva (2009), existe um círculo vicioso que afeta aquelas pessoas que se engajam numa prática erótica dissidente: por não haver espaço de discussão da orientação sexual, opta-se pelo silêncio; noutro momento, quando se demonstra abertamente a sexualidade, esta se torna elemento de escárnio público.
O que novamente leva as pessoas a esconderem sua intimidade, exigindo o direito à privacidade e à indiferença, mas acabando, muitas vezes, no ostracismo social.

\section{Considerações finais}

No ethos contemporâneo, o corpo é tomado como referente máximo do sujeito, ele constrói sua subjetividade, anexa adereços que indicam seu status social, suas preferências e gostos. Com as novas tecnologias ligadas à biomedicina, já é possível sonhar com um "novo corpo", substituindo partes e utilizando próteses para potencializar nosso funcionamento.

As diferenças e os limites entre os sexos passaram a ser questionadas por diferentes grupos, demonstrando que a anatomia não é o destino. A mudança de sexo biológico já se tornou realidade para determinados segmentos. E outros grupos marcham nesse sentido questionando os determinantes de gênero. Essas mudanças caminham impulsionadas pelo mercado e pelo contexto social, que exigem de nós cada vez mais saúde e beleza, magreza e juventude.

As travestis, influenciadas por estas questões, atuam em seus corpos, adequando-os às demandas do mercado do sexo; mas, principalmente, agem sobre sua corporeidade na perspectiva de alcançar um ideal de beleza que as aproxime do feminino. Não sendo totalmente passivas às demandas, elas criam dispositivos para transformarem seus corpos utilizando saberes populares e práticas médicas na construção da corporeidade travesti. Rompendo barreiras de gênero, transformando práticas e ampliando o jogo da sedução, as travestis criam uma sintaxe erótica própria, ligada ao glamour e ao exótico.

As histórias de vida das travestis nos ajudam a compreender os significados que elas atribuem a esse processo de transformação. Uma travesti não se faz somente com roupas e adereços femininos, mas também com hormônios para arredondar o corpo, com silicone para dar forma e volume aos seios e quadris. A dor durante este processo dá sentido às suas vivências e marca suas histórias. Além disso, o ser travesti também se faz na pista, no contato com os clientes e cafetinas, madrinhas/mães - que ora acolhem ora maltratam - e ensinam os caminhos da noite no mercado sexo. A rivalidade e as amizades marcam também a vivência travesti, pois, ali está o espelho onde se deve olhar e onde são encontrados os modelos para subir e permanecer "em cima do salto."

A violência e a exclusão ainda são relatadas com frequência pelas travestis. E passam a constituir uma maneira de lidar com os outros e com elas mesmas. Ao verem seus corpos e seus desejos relegados ao segundo plano, acabam por adoecer e trilham caminhos "mais fáceis" para suportar a dor do ostracismo. As drogas, as bebidas, o "truque", dentre outros são usados pelas travestis como mecanismos para amenizar seu sofrimento. 
Além desses caminhos, há a tentativa de romper com o universo da prostituição, abrindo novos espaços para o corpo travesti e novos significados para a sua atuação. Trabalhar em restaurantes, em salões de beleza, em ONGs LGBT e em outros lugares, ainda que de forma limitada, representam mudanças para as travestis que buscam recuperar sua cidadania. A busca pelo fim da discriminação é um sonho comum relatado pelas travestis, que, desde sua infância, tiveram seus desejos cerceados a partir do momento que assumiram sua condição.

A vivência travesti se inscreve na perspectiva do desejo e do sonho colocados como motivadores da transformação resultando em um corpo ambíguo, "abjeto", desconcertante. Dessa forma, as travestis surgem não apenas como grupo social a ser compreendido, mas como forma de referendar a fugacidade e inconsistência dos corpos, apresentando-os como metáfora da transitividade inscrita nas sexualidades contemporâneas.

Enquanto sujeitos de suas vidas, as travestis buscam romper com determinadas situações a partir de seus esforços. Criando novas relações e buscando diferentes espaços, o corpo travesti é um nó de significações viventes e aberto a novas compreensões e novos estilos. Essa nova corporeidade trás desafios para a Psicologia que é chamada a dialogar com novos sujeitos sociais, com movimentos progressistas e reacionários e questões inéditas inseridas atualmente nas políticas de saúde como o abuso de medicamentos, a patologização das transexualidades, o aumento dos transtornos e sintomas somáticos, dentre outros.

\section{Referências}

Andrade, L. N. (2015). Travestis na escola. Assujeitamento e resistência à ordem normativa. São Paulo: Metanoia Editora.

Benedetti, M. (2005). Toda Feita: corpo e gênero das travestis. Rio de Janeiro: Garamond.

Bruns, M. A. (2007). A redução fenomenológica em Husserl e a possibilidade de superar os impasses da dicotomia subjetividade/objetividade. In: M. A. Bruns \& A. Holanda (Orgs). Psicologia e Pesquisa Fenomenológica: reflexões e perspectivas (p. 24-39). São Paulo: Alínea.

Castro, A., García, G. \& Rodríguez, I. (2006). La dimensión corporal desde el enfoque fenomenológico-existencial. Psicología desde el Caribe, Universidad del Norte, 17: 122-148.

Estrada-Mesa, A. \& Báez-Silva, A. (2009). Retóricas eróticas disidentes. UniversitasPsychologica, 8(3), 653-672.

Furlan, R. (2008). A questão do método na psicologia. Psicologia em Estudo, 13(1), 25-33.

Jayme, J. (2010). Travestis, transformistas, drag-queens, transexuais: montando corpo, pessoa, identidade e gênero. In: A. Castro (Ed.) Cultura contemporânea, identidades e sociabilidades: olhares sobre corpo, mídia e novas tecnologias (p. 13-38). São Paulo: Cultura Acadêmica.
Kulick, D. (2008). Travesti: prostituição, sexo, gênero e cultura no Brasil. Rio de Janeiro: Editora Fiocruz.

Le Breton, D. (2011). Antropologia do corpo e modernidade. Petrópolis: Vozes.

Matthews, E. (2011). Compreender Merleau-Ponty. Petrópolis: Vozes.

Merleau-Ponty, M. (2004). Conversas - 1948. São Paulo: Martins Fontes.

Merleau-Ponty, M. (2006). Fenomenologia da percepção. Rio de Janeiro: Martins Fontes.

Moreira, D. (2004). O método fenomenológico na pesquisa. São Paulo: Pioneira.

Nóbrega, T. (2010). Uma fenomenologia do corpo. São Paulo: Editora Livraria da Física.

Ortega, F. (2008). O corpo incerto. Corporeidade, tecnologias médicas e cultura contemporânea. Rio de Janeiro: Garamond.

Pelúcio, L. (2009). Abjeção e desejo. Uma etnografia travesti sobre o modelo preventivo de AIDS. São Paulo: FAPESP.

Pelúcio, L. (2011). Desejos, brasilidades e segredos: o negócio do sexo na relação entre clientela espanhola e travestis brasileiras. Bagoas - Estudos Gays: Gêneros e Sexualidades, 5(6), 243-266.

Peres, W. (2011). Travestis: corpos nômades, sexualidades múltiplas e direitos políticos. Em: F. Souza \& T. Sabatine (Eds.). Michel Foucault: sexualidade, corpo e direito (p. 163-178). São Paulo: Cultura Acadêmica.

Peres, W. (2015). Travestis brasileiras: dos estigmas à cidadania. Curitiba: Juruá.

Sabino, C. (2004). O peso da forma - cotidiano e uso de drogas entre fisiculturistas. Tese (Doutorado em Ciências Humanas - Sociologia). Universidade Federal do Rio de Janeiro, Rio de Janeiro.

Edmar Henrique Dairell Davi - Possui Graduação e Mestrado em Psicologia pela Universidade Federal de Uberlândia, e Doutorado em Psicologia pela FFCLRP/USP. Docente da Universidade Federal do Recôncavo da Bahia. Endereço Institucional: Av. Carlos Amaral, 1015, Cajueiro, Santo Antônio de Jesus, Bahia. CEP: 44.574-490. E-mail: edmardavi@yahoo.com.br

Maria Alves de Toledo Bruns - Docente e pesquisadora do Programa de Pós-Graduação em Psicologia da Faculdade de Filosofia, Ciências e Letras de Ribeirão Preto - USP.

Recebido em 28.06.16 Primeira Decisão Editorial em 30.09.16 Aceito em 02.02.17 